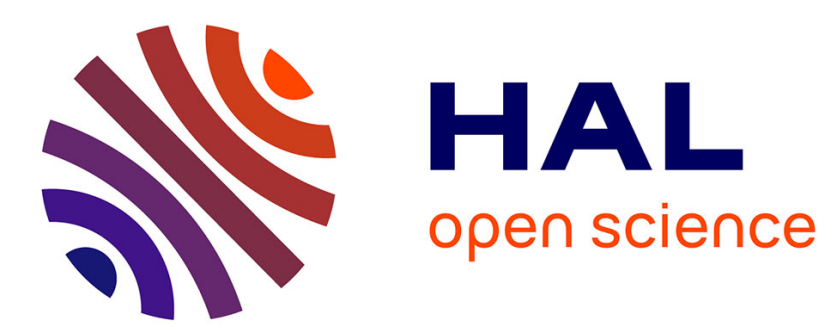

\title{
Comparison of various milling technologies for grinding pharmaceutical powders
}

\author{
M Nakach, J R Authelin, Alain Chamayou, John A. Dodds
}

\section{To cite this version:}

M Nakach, J R Authelin, Alain Chamayou, John A. Dodds. Comparison of various milling technologies for grinding pharmaceutical powders. International Journal of Mineral Processing, 2004, 74 (1), pp.S173-S181. 10.1016/j.minpro.2004.07.039 . hal-01667191

\section{HAL Id: hal-01667191 \\ https://hal.science/hal-01667191}

Submitted on 8 Nov 2018

HAL is a multi-disciplinary open access archive for the deposit and dissemination of scientific research documents, whether they are published or not. The documents may come from teaching and research institutions in France or abroad, or from public or private research centers.
L'archive ouverte pluridisciplinaire HAL, est destinée au dépôt et à la diffusion de documents scientifiques de niveau recherche, publiés ou non, émanant des établissements d'enseignement et de recherche français ou étrangers, des laboratoires publics ou privés. 


\title{
Comparison of various milling technologies for grinding pharmaceutical powders
}

\author{
Mostafa Nakach ${ }^{\mathrm{a}}$, Jean-René Authelin ${ }^{\mathrm{a}}$, Alain Chamayou, ${ }^{\mathrm{b}, *}$, John Dodds $^{\mathrm{b}}$
}

${ }^{\mathrm{a}}$ Aventis Pharma, 13 Quiai Jules Guesde, 94400 Vitry sur Seine, France
${ }^{\mathrm{b}}$ Ecole des Mines d'Albi-Carmaux, Campus Jarlard, 81013 Albi, France

\begin{abstract}
This paper examines fine grinding techniques in current use in the pharmaceutical industry. Experimental results are given for fine grinding of vitamin $\mathrm{C}$, chosen as a model substance representative of pharmaceutical products, using eight different grinding mills chosen amongst those in current use in the pharmaceutical industry. The results are evaluated in terms of product quality expressed as particle size and distribution and also in terms of operating criteria applicable in the pharmaceutical industry such as ease of setting up, ease of cleaning, and investment cost. The main conclusion reinforces and quantifies current practice of using pancake mills that are preferred for ultra fine grinding as they are simple to use, can treat high feed rates and are easy to clean.
\end{abstract}

Keywords: fine grinding; pharmaceutical industry; pancake mill

\section{Introduction}

In recent years and particularly in the pharmaceutical industry, product quality criteria have become more and more draconian, imposing specifications involving finer particles and closer control on the mean particle size, or the width and cut-off of the particle size distribution. Additional requirements are for the particle shape and surface properties of powders, which go towards the end use consumer requirements.

* Corresponding author. Tel.: +33 5634930 28; fax: +33 563 493025 .

E-mail address: achamayo@enstimac.fr (A. Chamayou).
The past 10 years have also seen the development of new grinding technologies as well as significant improvements to existing methods. Nevertheless, size reduction by grinding has remained an essentially empirical science, but one needing a better understanding so as to meet new technical and economic requirements.

The theory of grinding has mainly been developed in the mineral industry as a response to needs for maximising production capacity and minimising energy use for low value added products (Prasher, 1987). On one hand, literature gives many examples of experimental investigations with different types of mill and numerous types of mineral powders for validating models of grinding as a 
unit operation applicable in such circumstances. On the other hand, there is a paucity of literature results for the food and pharmaceutical industries. This is partly due to the fact that products from natural sources are more variable, making investigation difficult to generalise, and partly due to the fact that in high value added industries, experimental results are often considered confidential. Accordingly, the scarce published data often conceals the nature and properties of the powders used, thus making it even more difficult to generalise the results.

Grinding operations in the pharmaceutical industry are generally limited to three or four main types of equipment, the choice between which is usually based on experience and limited by the fact that more fundamental approaches have been developed for the mineral industries. It is difficult to take into account the properties of organic materials and the process needs of the pharmaceutical industry. In this industrial area, the main factor of choice is the ability to give a certain product quality, in terms of fineness of particle size or specific surface, without causing physical or chemical changes such as amorphisation. Further criteria are the ease of determining operating parameters and ease of cleaning so as to eliminate contamination which are both specially important in multi-product installations. Finally investment costs must be borne in mind though they could be secondary in the case of high value added products.

The experimental investigation presented here is based on comparative grinding tests using vitamin $\mathrm{C}$, a low-cost model pharmaceutical product for which much information is available in the literature. This substance is non-toxic, easy to remove by conventional cleaning and readily available at a reasonable price, making it suitable for pilot plant tests. It is a good analogue of many pharmaceutical powders where fine particle size is required to improve dissolution, chemical reactivity and the homogeneity in powder mixtures, etc.

\section{Methods}

\subsection{Types of mill used}

Two families of grinding mill have been tested: air jet mills and impact mills. The main details of the equipment used are given in Table 1.

\subsection{Powder used}

Vitamin $\mathrm{C}$ is used in this investigation as a nontoxic model pharmaceutical product having mechanical properties typical of organic powders. It is available in large quantities at a reasonable price and does not pose problems of cleaning the equipment. The main physical properties are as follows: Crystalline particles with size $X_{10}=27.8 \mu \mathrm{m}, X_{50}=$ $122.8 \mu \mathrm{m}, X_{90}=295.2 \mu \mathrm{m}$, Blaine specific surface $=$ $0.06 \mathrm{~m}^{2} / \mathrm{g}$, bulk density $=0.9 \mathrm{~g} / \mathrm{ml}$.

\subsection{Characterisation equipment and methods}

The ground powder produced in the various tests has been characterised by the methods given in Table 2.

These measurements indicate that: the median diameter determined by the Insitec in line laser

Table 1

Types of mill used in the study

\begin{tabular}{|c|c|c|c|c|c|c|c|c|}
\hline Type of mill & Air jet & & & Impact & & & & \\
\hline Model & $\begin{array}{l}\text { Spiral jet } \\
\text { Pancake } \\
\text { Mill }\end{array}$ & $\begin{array}{l}\text { Oval ring } \\
\text { Mill }\end{array}$ & $\begin{array}{l}\text { Fluidised bed } \\
\text { with integral } \\
\text { selector }\end{array}$ & $\begin{array}{l}\text { Simple rotor } \\
\text { pin mill }\end{array}$ & $\begin{array}{l}\text { Simple rotor } \\
\text { pin mill }\end{array}$ & $\begin{array}{l}\text { Double rotor } \\
\text { pin mill }\end{array}$ & $\begin{array}{l}\text { Pin mill with } \\
\text { selector }\end{array}$ & $\begin{array}{l}\text { Fixed } \\
\text { hammer } \\
\text { mill }\end{array}$ \\
\hline Maker & Alpine & $\begin{array}{l}\text { Fluid Energy } \\
\text { Aljet }\end{array}$ & Alpine & Forplex & Alpine & Alpine & $\begin{array}{l}\text { Micron } \\
\text { system }\end{array}$ & Forplex \\
\hline Size & $100 \mathrm{~mm}$ & & $0.8 \mathrm{~L}$ & 100 & 160 & 250 & & 100 \\
\hline Reference & AS100 & & AFG100 & BLX & & & MS20 & BLX \\
\hline
\end{tabular}


Table 2

Measurements made on ground products

\begin{tabular}{|c|c|c|c|}
\hline Property & Method & Instrument & Pertinence \\
\hline \multirow[t]{2}{*}{$\begin{array}{l}\text { Particle size } \\
\text { distribution }\end{array}$} & $\begin{array}{l}\text { Laser } \\
\text { diffraction }\end{array}$ & Malvern & $\begin{array}{l}\text { Product quality } \\
\text { control with respect } \\
\text { to specifications }\end{array}$ \\
\hline & & Insitec & $\begin{array}{l}\text { In line continuous } \\
\text { measurement of } \\
\text { product quality. } \\
\text { Ensures traceability, } \\
\text { correlated to Malvern }\end{array}$ \\
\hline $\begin{array}{l}\text { Specific } \\
\text { surface }\end{array}$ & Permeability & Blaine & $\begin{array}{l}\text { Robust, simple to use } \\
\text { Correlated to the } \\
\text { median diameter IPC }\end{array}$ \\
\hline Density/flow & Tap density & & $\begin{array}{l}\text { Described in the } \\
\text { European Pharmacopia } \\
\text { Correlated to the } \\
\text { median diameter IPC }\end{array}$ \\
\hline
\end{tabular}

diffraction instrument is not identical to that determined by the Malvern laser diffraction instrument but the two methods are well correlated by a straight line relation such that

$X_{50 \text { Insitec }}=1.3534 X_{50 \text { Malvern }}-1.5549$

This result has also been confirmed by other results with different products.

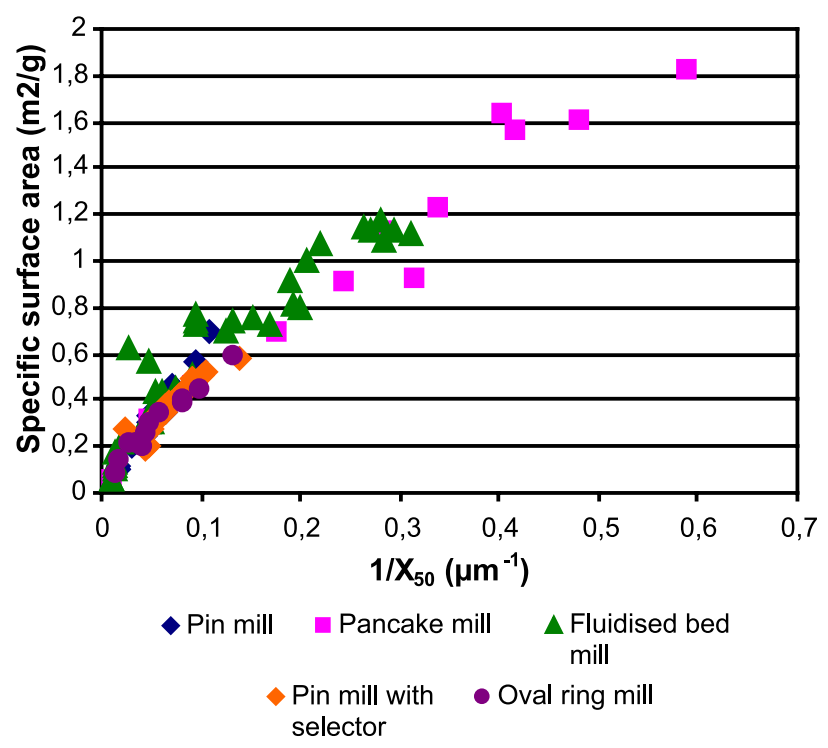

Fig. 1. Specific surface as a function of the reciprocal of the median diameter: Pin mill, Pancake mill, Fluidised bed mill, Pin mill with classifier, Oval ring jet mill.

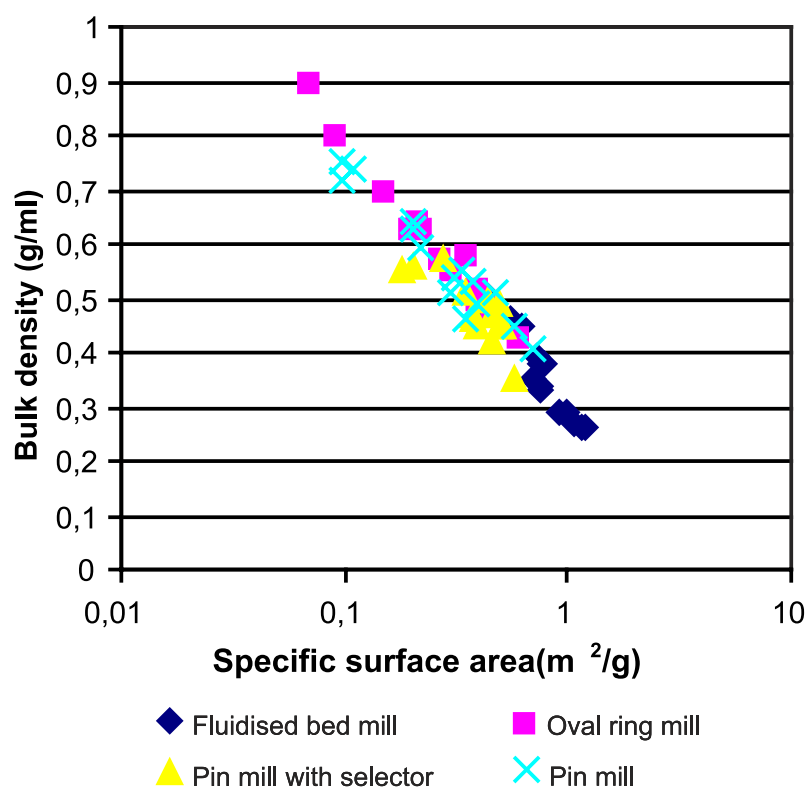

Fig. 2. Bulk density as a function of the specific surface.

For all grinding methods, the specific surface of the ground product is inversely proportional to the median diameter. See Fig. 1.

For all grinding methods the bulk density of the products decreases as the specific surface increases (see Fig. 2).

These results confirm the coherence of the different methods used for characterising the ground products.

\section{Experimental procedures}

\subsection{Air jet milling}

\subsubsection{Spiral jet "pancake" mill}

The mill comprises a flat cylindrical grinding chamber with a ring of air nozzles each set at an angle to the circumference of the chamber. These jets form a so-called grinding circle and a free vortex, which plays the role of a selector by pushing the un-ground particles outwards and sucking the fine ground particles to the centre of the chamber. After leaving the grinding chamber the product goes through a cyclone to separate the coarse particles (recovered in a container) from the fine product (recovered in the filter). 
A priori, the main operating parameters are as follows:

- The gas pressure used for grinding and the solids feed rate determine the specific energy used for grinding $\left(E_{\mathrm{sp}}\right)$

$$
E_{\mathrm{sp}}=\frac{E_{\mathrm{c}}}{Q_{\text {solid }}} \propto \frac{P}{Q_{\text {solid }}},
$$

where $E_{\mathrm{c}}$ is the kinetic energy of the gas used for grinding, $Q_{\text {solid }}$ is the solids feed rate and $P$ the absolute pressure of the gas used for grinding.

- The geometry of the nozzles

- The number of nozzles

- The angle the nozzles make to the tangent at the circumference

To evaluate the grinding performance these latter three parameters were kept constant and the grinding pressure and the solid feed rate were varied. The results shown in Fig. 3 indicate that the specific surface of the ground product is mainly influenced by the specific energy used for grinding.

\subsubsection{Oval ring mill}

The oval ring mill has an oval vertical grindingchamber divided into two parts.

A lower part where grinding takes place and an upper part where classification occurs. Particles are introduced in the lower part of the mill using a Venturi feed system and breakage is caused by the air jets projecting particles at one another. In the upper-part, centrifugal force pushes the coarse particles to the outside of the chamber to be recycled in the grinding section. The fine particles go to the inside of the grinding chamber ring where they exit and are collected in a filter.

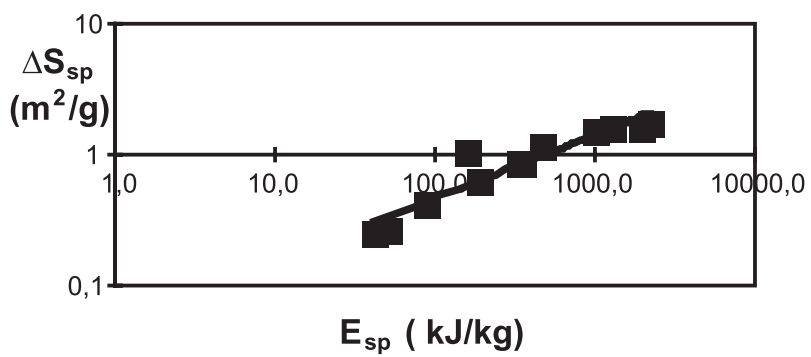

Fig. 3. Specific surface created as a function of the specific energy used for grinding in the spiral jet pancake mill.

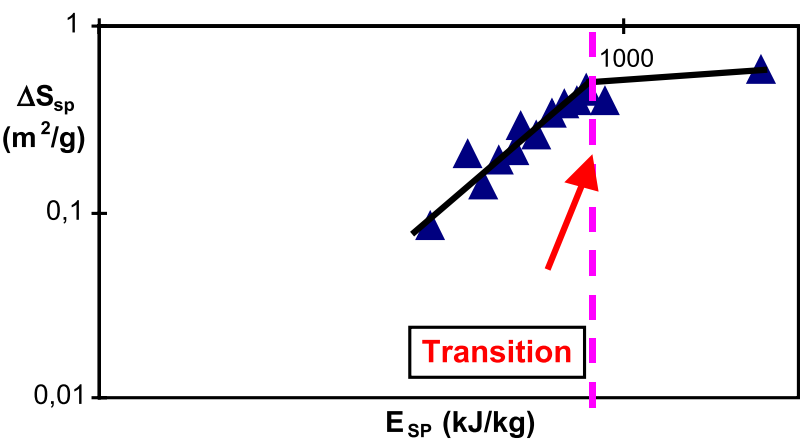

Fig. 4. Created specific surface as a function of the specific energy used for grinding in the oval ring mill.

A priori, the main operating parameters in this type of mill are the same as those important in the spiral jet pancake mill described above. Experimental results are given in Fig. 4 and show that the specific surface of the ground product depends essentially on the specific energy used for grinding. In addition, there are two regimes.

A low-pressure regime dominated by fragmentation, and a high-pressure regime dominated by attrition where pressure has a less marked effect.

\subsubsection{Fluidised bed air jet mill with integral classifier}

This mill has a cylindrical grinding chamber of diameter $100 \mathrm{~mm}$ fitted in its lower part with a cone having three $2 \mathrm{~mm}$ air jets pointing at each other. Fragmented particles are carried to a "squirrel cage" type turbo selector, the speed of rotation of which can be varied between 18,000 and 20,000 rpm, which is located in the upper part of the mill chamber.

Solid is introduced in the mill by a screw feeder, the product leaving the mill through the selector is collected in a cyclone and the transport air is further filtered to recover ultra-fine particles. The air jets form a fluidised bed of particles in the chamber and grinding occurs by projection of particles against one another. These particles are then carried upwards by the current of air to the turbo selector which only allows particles less than a certain size, determined by the speed of rotation, to leave the grinding chamber. Particles larger than the cut size are excluded by centrifugal force and return to the grinding section. The mill used in the tests also has an Insitec on line laser diffraction instrument, which gives continuous determination of the particle size distribution and also a measure of the solids flow rate from the attenuation of the light beam. 
A priori, the important operating parameters of this type of mill are: The air pressure at the grinding nozzles, the solids feed rate, and the speed of rotation of the turbo selector.

Experiments performed by varying these parameters show:

- The specific surface of the product depends on the air pressure used for grinding $(P)$ and the speed of rotation of the selector $(N)$. As shown in Fig. 5, these two parameters seem to be linked together and similar results are obtained by keeping constant

$$
\frac{P}{N^{2}} \propto \frac{\text { drag force }}{\text { centrifugal force }}
$$

- In the range used here (1 to $10 \mathrm{~kg} / \mathrm{h}$ ) the solids feed rate has little influence on the specific surface of the product. The particle size is essentially controlled by the classifier that compensates the feed rate effects by recycling coarse particles in the grinding zone of the mill. It should be noted that with some products this mechanism can affect the particle morphology whilst still respecting size specifications. Moreover, the recycling of coarse particles causes an increase in the mill hold-up. This behaviour is also observed up to a feed rate flooding value when overflow of the classifier occurs. This importance of the influence of the classifier explains the pertinence of the $\left(P / N^{2}\right)$ parameter to describe the experimental results.

- The Insitec on line measuring system showed that the instantaneous product particle size $X_{50}$ and $X_{90}$ vary considerably during operation but that the $X_{10}$ is more stable.

- In addition, it is found that the time required to establish a continuous operating regime depends on the solids feed rate and indications are that there is a solids hold up in the mill of about $240 \mathrm{~g}$.

\subsection{Impact mills}

\subsubsection{Pin mills}

A pin mill comprises two disks fitted with overlapping pins. One of the disks (stator) is stationary the other (rotor) rotates with a high peripheral speed of up to $150 \mathrm{~m} / \mathrm{s}$. Product is introduced by a feed screw in the centre of the mill and leaves by the periphery to a collecting filter.

The main operating parameters varied in the experimental programme were the speed of rotation and the solids feed rate. In addition, the feed solids particle size was varied by making several passes through the same mill and the effect of the size of the mill was examined by using three different mills.

Fig. 6 shows that for the sizes of mill used, the specific surface of the product varies linearly with the square of the peripheral speed up to a value of $150 \mathrm{~m} /$ s. Above this value there is a change in slope. This indicates that the square of the peripheral speed is the main factor for scale up.

It is found that the solids feed rate has only a very minor effect on product quality that with respect to the speed of rotation. It is also found that, after two passes

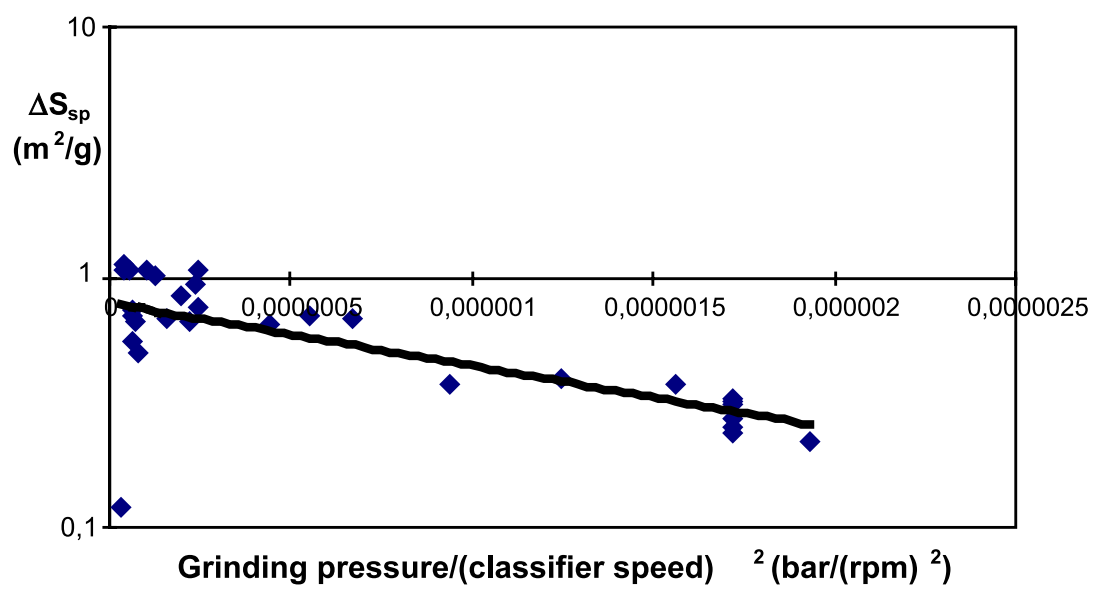

Fig. 5. Specific surface created as a function of the factor $P / N^{2}$ for the fluidised bed air jet mill. 


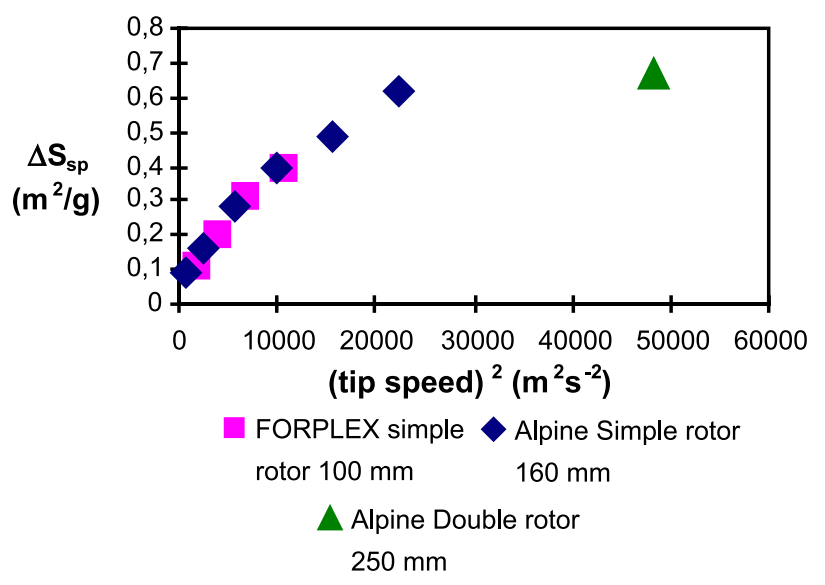

Fig. 6. Specific surface created as a function of the square of the peripheral speed for three sizes of pin mill: * Pin mill, * Double rotor pin mill.

through the mill, the product quality remains essentially constant.

\subsubsection{Fixed hammer mill}

In the case of a fixed hammer mill the feed is to the centre of the mill where it is thrown at a selector grid by the centrifugal force created by the rotating blades.

The particles are ground by successive impacts on the blades or between the particles and the grill. Peripheral speeds are in the range 50 to 100 $\mathrm{m} / \mathrm{s}$. Fixed hammer mills require high air ventilation to eliminate heat created by grinding. A priori the important operating parameters are, the peripheral speed of the rotor, the solids feed rate, the air flow rate and the characteristics of the selector grill: size and shape of the holes and free area of the holes.

The parameters varied in the experimental programme were the solid flow rate, the speed of rotation of the rotor, the type of grill and the hole size. Results given in Fig. 7 show that the specific surface of the ground product depends essentially on the square of the speed of rotation and that the type of grill has an important influence on product quality. For example, a punched hole grill gives the highest specific surface but the size of the holes has very little effect on grinding performance. It is also found that the solids flow rate has little influence on product quality as determined by the specific surface.

\subsubsection{Pin mill with dynamic selector}

The type of pin mill with dynamic selector used is a Micron System MS20 model, which has a pin mill coupled to a dynamic selector with solid feed through a pair of synchronised valves. A fan is fitted upstream from the mill to create a strong air flow through the grinding chamber of 100 to $320 \mathrm{~m}^{3} / \mathrm{h}$. Final product is collected in a bag filter with cleaning system and a product recovery container. The mill used has a cylindrical chamber and a grinding rotor with eight teeth (diameter $6 \mathrm{~mm}$, height $15 \mathrm{~mm}$ ) turning at up to $10,000 \mathrm{rpm}$ depending on the speed of the selector. The selector has 12 blades and rotates at up to 5000 $\mathrm{rpm}$. Solid is introduced by the valve system to the circumference of the grinding chamber and ground product is carried by the air flow towards the selector ring where centrifugal force throws the coarse particles back into the grinding chamber and the fines are carried to the collector filter. The main operating parameters are the speed of the grinding rotor, the speed of the selector rotor, the solids feed rate and the air flow rate.

The experimental programme showed that product quality is essentially governed by the performance of the selector. The specific surface depends on the air pressure $(P)$ and the speed of rotation of the selector $(N)$. Fig. 8 shows that these two parameters seem to be linked together and similar results are obtained for similar values of the group:

$\frac{P}{N^{2}} \propto \frac{\text { drag force }}{\text { centrifugal force }}$

It is further found that the speed of rotation of the grinding rotor has little effect on the specific

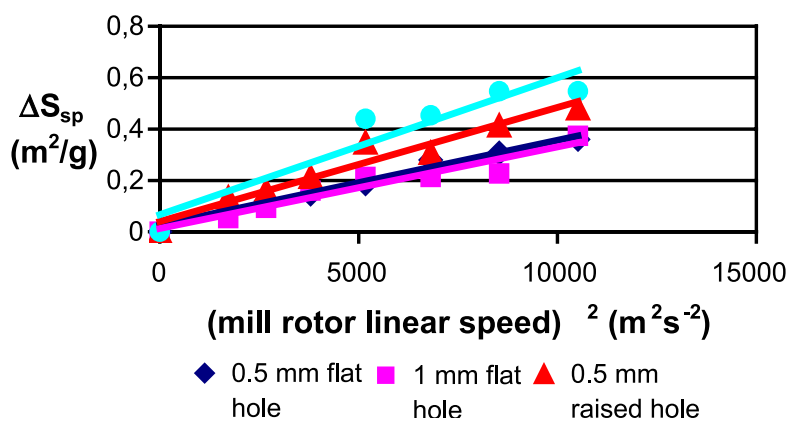

Fig. 7. Specific surface created as a function of the square of the speed of rotation in fixed hammer mills for different grid types. 


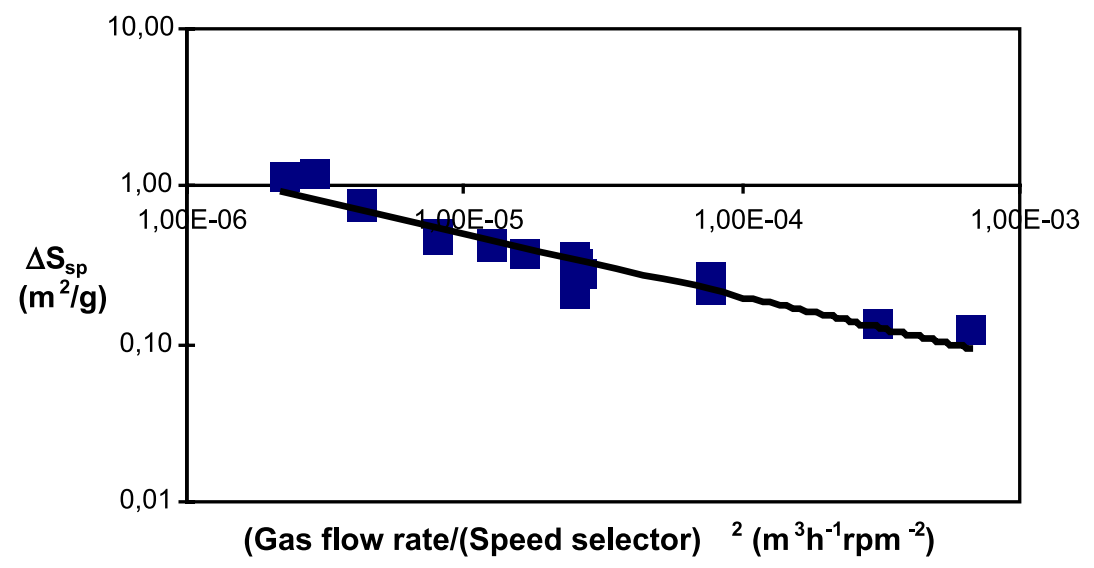

Fig. 8. Specific surface created as a function of the factor (air flow rate/(classifier speed) ${ }^{2}$ ) in a pin mill with dynamic selector.

surface of the product and that the solids flow rate has practically no effect on the product specific surface, which does however vary with the speed of rotation of the classifier. Repeated passages through the mill show that there is practically no change in product quality after the first passage through the mill. Up to a maximum value of the feed rate this phenomena are consequences of the importance of the classification process and coarse particles recycling to determine the output size of the product.

\section{Summary of the main results}

The main results of the study may be resumed as follows:

Product quality from an air jet mill depends mainly on the specific energy used (ratio of kinetic energy of the gas to the solids feed rate).

Product quality from a fluidised bed type air jet mill is mainly controlled by the performance of the turbo selector.

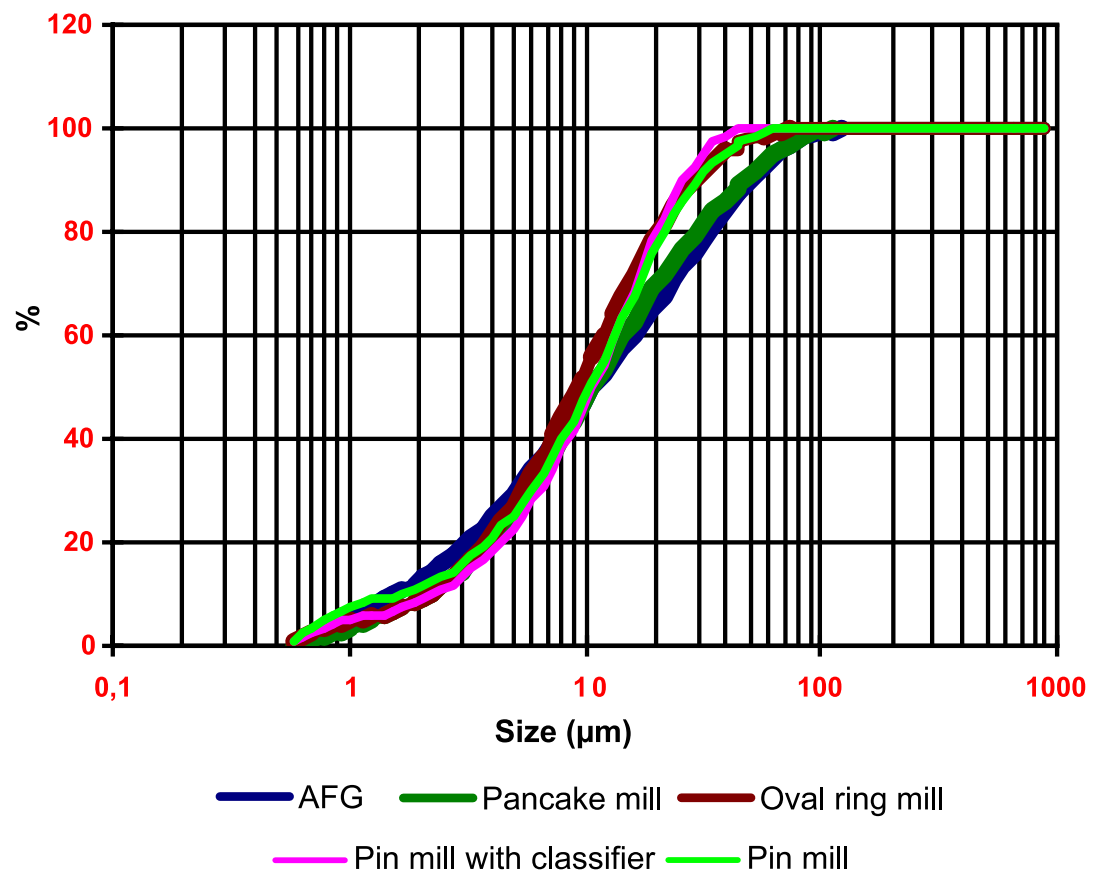

Fig. 9. Particle size distributions of products from five different types of mill. 
Product quality from an impact type mill (pin mill, hammer mill) is mainly determined by the speed of rotation of the grinding rotor.

Product quality from a pin mill coupled with a selector is mainly governed by the performance of the selector.

\section{Comparison of the different types of mill}

The different types of mill can be compared on the basis of:

- The specific surface of the product, the width of the particle size distribution expressed as the span defined as:

$\Psi=\frac{X_{90}-X_{10}}{2 X_{50}}$

where $X_{90}, X_{50}$ and $X_{10}$ are the quantiles at $90 \%, 50 \%$ and $10 \%$, respectively.

- The ease of use with respect to the production capacity of the mill,

- Cleaning,

- Investment costs.

Comparison shows that pancake mills give the smallest particle with the highest specific surface $\left(S_{0}>1.7 \mathrm{~m}^{2} / \mathrm{g}\right.$ that is $\left.X_{50}<2 \mu \mathrm{m}\right)$.

The two types of mill having integral selectors, that is the fluidised bed air jet mill and the MS20

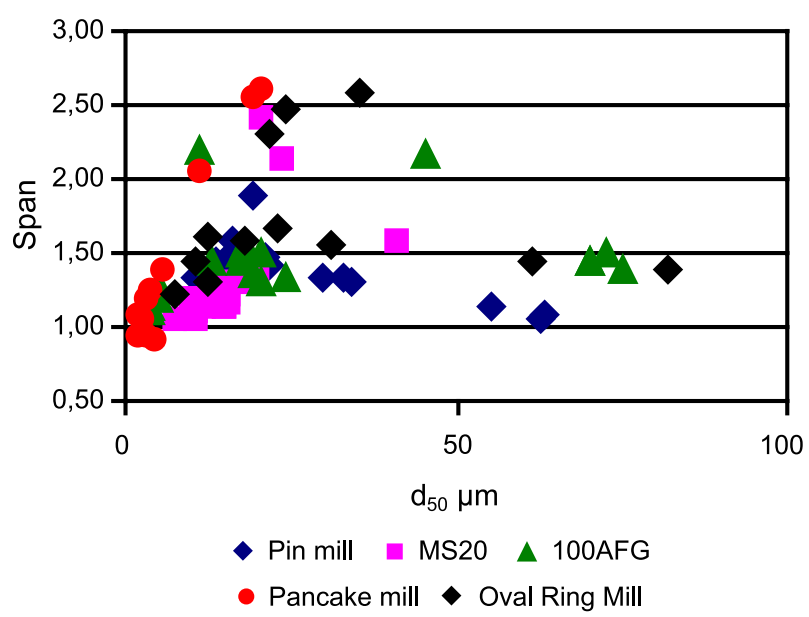

Fig. 10. Span of the size distributions from five different types of mill.

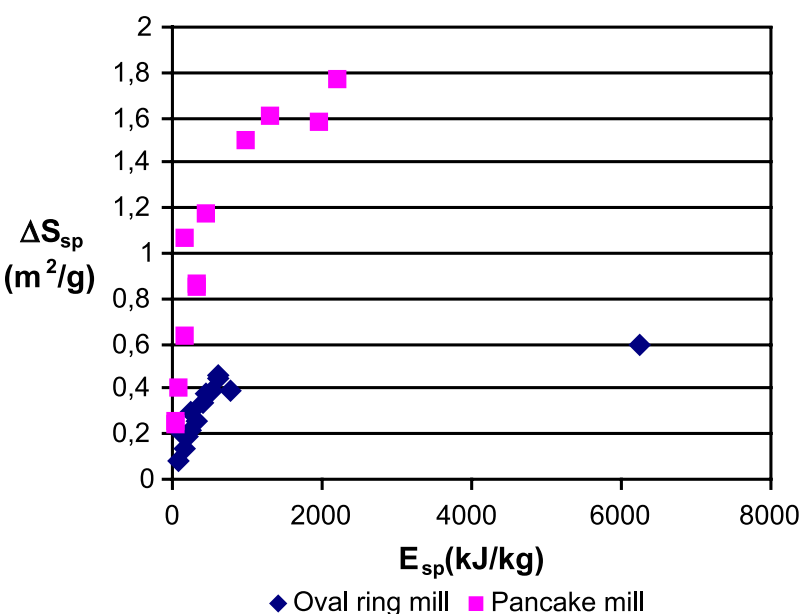

Fig. 11. Specific surface created as a function of specific energy for the oval ring mill and the pan cake mill.

pin mill, also give very high specific surface products $\left(S_{0}>1 \mathrm{~m}^{2} / \mathrm{g}\right.$ that is $\left.X_{50}<5 \mu \mathrm{m}\right)$. However, for finer grinding the pancake mill gives better results in terms of fineness of particle size and narrowness of size distribution. This is illustrated in Figs. 9 and 10.

For equal specific energy, the pancake mill is more efficient than the oval ring mill and consequently the latter is best suited to producing low specific surface products (Fig. 11).

In the domain of fine grinding $\left(5 \mu \mathrm{m}<X_{50}<20\right.$ $\mu \mathrm{m})$ the MS20 mill is very efficient and gives a narrow product size distribution. However, the fluidised bed air jet mill is rather disappointing as it gives a rather wide size distribution. It may be noted that the fixed hammer mill and the fluidised bed air jet mill are more susceptible to flooding than the other mills. Finally cleaning and validation of operation take longer in machines with moving parts.

\section{Conclusions}

In this investigation, comparison is made of the performance of eight different mills for fine grinding a model pharmaceutical powder. The results summarised in Table 3 lead to the following conclusions: The pancake mill is preferred for ultra fine grinding as it is simple to use, can treat high feed rates and is easy to clean. 
Table 3

Summary of conclusions

\begin{tabular}{|c|c|c|c|c|c|}
\hline Type of mill & $\begin{array}{l}\text { Product specific } \\
\text { surface }\left(\mathrm{m}^{2} / \mathrm{g}\right)\end{array}$ & $\begin{array}{l}\text { Maximum } \\
\text { feed rate }\end{array}$ & Cleaning & Operation & Price $(\mathrm{kF})$ \\
\hline Pancake mill & 1.77 & $10 \mathrm{~kg} / \mathrm{h}$ & Easy & $\begin{array}{l}\text { Mechanically simple, } \\
\text { little or no maintenance }\end{array}$ & 200 \\
\hline Oval ring mill & 0.59 & $30 \mathrm{~kg} / \mathrm{h}$ & Easy & $\begin{array}{l}\text { Mechanically simple, } \\
\text { little or no maintenance }\end{array}$ & 200 \\
\hline Fluid bed + selector & 1.12 & $\begin{array}{l}7 \mathrm{~kg} / \mathrm{h} \text { for } N<7000 \mathrm{rpm} \\
2.5 \mathrm{~kg} / \mathrm{h} \text { for } N>7000 \mathrm{rpm}\end{array}$ & Difficult & $\begin{array}{l}\text { Mechanically complex, } \\
\text { requires regular } \\
\text { maintenance }\end{array}$ & 1000 \\
\hline Pin mill (100 mm) & 0.41 & $25 \mathrm{~kg} / \mathrm{h}$ & Less easy & $\begin{array}{l}\text { Requires regular } \\
\text { maintenance }\end{array}$ & 250 \\
\hline Fixed hammer mill & 0.52 & $\begin{array}{l}25 \mathrm{~kg} / \mathrm{h} \text { for } d_{\text {grid }} \geq 0.3 \mathrm{~mm} \\
7 \mathrm{~kg} / \mathrm{h} \text { for } d_{\text {grid }}<0.3 \mathrm{~mm}\end{array}$ & Less easy & $\begin{array}{l}\text { Requires regular } \\
\text { maintenance }\end{array}$ & 250 \\
\hline Pin mill+selector & 1.22 & $75 \mathrm{~kg} / \mathrm{h}$ & Difficult & $\begin{array}{l}\text { Requires regular } \\
\text { maintenance }\end{array}$ & 500 \\
\hline
\end{tabular}

For fine or coarse grinding the oval ring mill and the pin mill are comparable. The MS20 can be useful if tight size distributions are required. Finally, the fluidised bed air jet mill does not seem to be well suited to grinding organic powders. This type of mill does not have any particular qualities with respect to particle size and distribution, has only a low capacity, is rather expensive, and not very easy to use.

\section{Reference}

Prasher, C.L., 1987. Crushing and Grinding Process Handbook. John Wiley, London. 